\author{
Reseña de la obra: \\ VALORES DE LA CLÍNICA. \\ EMOCIONES QUE GUIIAN EL TRATAMIENTO PSICOANALÍTICO ${ }^{1}$
}

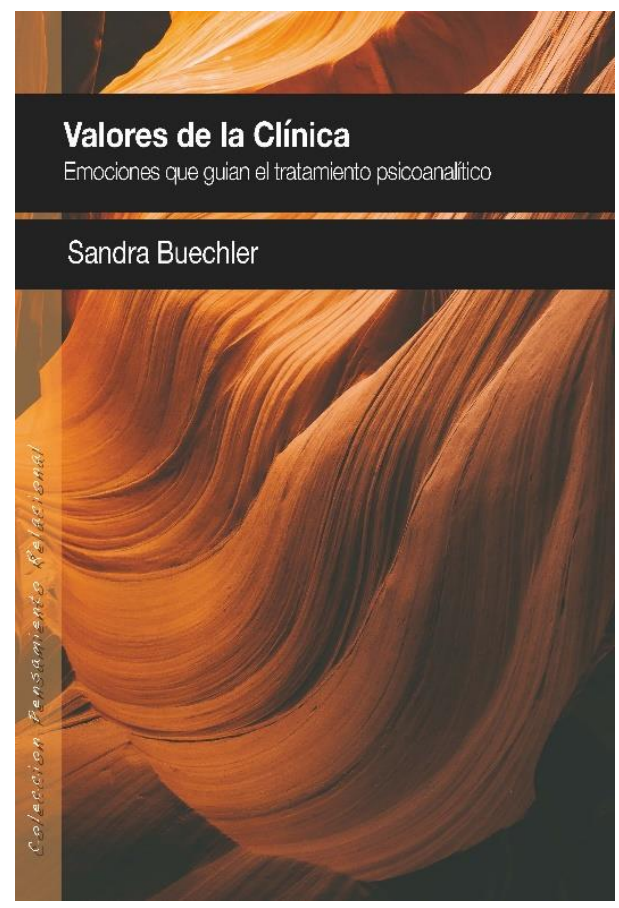

\author{
Sandra Buechler \\ Madrid: Ágora Relacional, 2018 \\ Colección Pensamiento Relacional $n^{\circ} 20$
}

\title{
Realizada ${ }^{1}$ por Lucía Blanco Rejas ${ }^{2}$
}

\section{RESUMEN}

Este libro se refiere al estilo personal que Sandra Buechler hace de la teoría de las emociones, para saber qué escuchar del lenguaje del paciente, y con la convicción puesta en la importancia que desempeñan las emociones en la experiencia humana. Y lo hace nombrándolos con palabras que empleamos en la vida diaria: valentía, esperanza, afabilidad, equilibrio emocional, capacidad de superar las pérdidas, la integridad...eso conecta con el paciente y a su vez él nos conmueve y despierta esas cualidades como parte de nuestro potencial.

\footnotetext{
${ }^{1}$ Blanco Rejas, L. (2018). Reseña de la obra de Sandra Buechler: "Valores de la Clínica. Emociones que guían el tratamiento psicoanalítico". Clínica e Investigación Relacional, 12 (3): 584-602. [ISSN 19882939] [Recuperado de www.ceir.info] DOI: 10.21110/19882939.2018.120312
} 
Y examinando los intereses vitales del tratamiento tanto para el paciente como para el analista, plantea unas interesantes cuestiones a propósito del significado de nuestra vida como terapeutas. ¿Cómo reaccionamos ante la vergüenza de los errores, ante nuestras necesidades narcisistas con los lapsus, cuando el paciente se queja de que no le ayudamos, cuando cuestiona el valor de nuestro trabajo, o el del tratamiento, cuánto necesitamos de los éxitos en las sesiones?. Dice Buechler que puede que hacer una autorevelación en sí misma no sea ésta lo que ayudó, sino los valores que se dan a conocer en ese acto.

\section{ABSTRACT}

This book refers to the personal style that Sandra Buechler makes of the theory of emotions, to know what to hear from the patient's language, and with the conviction placed on the importance of emotions in human experience. And she does so by naming them with words we use in daily life: courage, hope, affability, emotional balance, ability to overcome losses, integrity ... that connects with the patient and in turn he moves us and awakens those qualities as part of our potential.

And by examining the vital interests of treatment for both the patient and the analyst, she raises some interesting questions about the meaning of our life as therapists. How do we react to the shame of mistakes, to our narcissistic needs with lapses, when the patient complains that we do not help him, when he questions the value of our work, or the treatment, how much do we need success in the sessions? Buechler says that it may be that self-disclosure itself is not what helped, but the values that are revealed in that act.

Palabras Clave: Curiosidad, bondad, valentía, esperanza, modularidad de las emociones

Key Words: Curiosity, kindness, courage, hope, modularity of emotions

\section{INTRODUCCIÓN}

Primero de todo, me uno absolutamente a las palabras de Alejandro Ávila: "conocer la obra de Sandra Buechler y a la persona, ha sido una de las experiencias más enriquecedoras de mi vida clínica...Nadie como ella ha sabido transmitir la sutileza de las emociones ..." Pág. 15). Y lo digo con plena convicción, ya que hice la reseña de su libro "Marcando La Diferencia En La Vida De Los Pacientes. Experiencia Emocional En El Ámbito Terapéutico" (2015), que fue editado también por Ágora Relacional. Y esto, junto a la lectura de alguno de sus artículos y conocerla personalmente, me da alas para hacer esta aseveración.

En la revisión de la $2^{a}$ edición en castellano, podemos leer que Sandra Buechler comienza con una declaración de intenciones. Dice: "el libro explora la curiosidad, la esperanza, la amabilidad, el coraje, el sentido del propósito, la capacidad de soportar la pérdida y la integridad en la cultura del psicoanálisis". (pág.11).

Las primeras páginas están dedicadas a hacer una presentación previa del desarrollo que hará después en los sucesivos capítulos, los cuales describirá y acompañará de casos prácticos. Eso ayudará a que nos podamos enmarcar en la lectura preferente que necesitemos o que queramos hacer. 
Desarrolla la curiosidad como una emoción que es determinante en el tratamiento intersubjetivo, y como protectora contra el desgaste. La curiosidad debe ser auténtica, supone deseos reales de conocer al paciente y a nosotros mismos. "Estar juntos para ser curiosos", dice (pág. 49). Cuando aparece la curiosidad siempre habrá un perseguir una idea, una conexión, una asociación por el deseo de descubrirla. Sandra lo llama plantear "un desafío relacional" (pág. 62)

Trata la bondad como fuente de inspiración allá donde se dé un tratamiento que acabe con éxito. Pero, afirma, se necesita que a esta emoción se le dé la importancia que tiene, porque aún está poco valorado en la técnica analítica.

Resalta el coraje como eje en el tratamiento para enfrentarse a momentos difíciles donde haya de mostrarse incluso lo no conveniente,

Y la veracidad, la esperanza y el valor. Todos importan para que nuestros pacientes logren una mejor calidad de vida.

Refiriéndose a la envidia cita a Feiner 1986 que la definió como dar "forma al deseo": el sentimiento de envidia puede utilizarse para clarificar lo que queremos de la vida. (pág. 187). Será, pues una fuente de información que provendrá de la habilidad que genera el tratamiento cuando aumenta la experiencia emocional dolorosa.

Sobre la soledad, Sandra habla de lo difícil que es sentirnos solos y de la dificultad para evitar el esfuerzo que hemos de hacer, pero afirma que "podemos encontrarnos menos solos si nuestra mente está abastecida con conceptos familiares y objetos internos supervisores bien establecidos. Estas nociones e identificaciones, íntimamente conocidas, pueden afianzar al analista... estos conceptos me ayudan a sentir que sigo siendo yo cuando realizo el trabajo a mi modo, aun cuando en algunos aspectos trabaje de manera distinta lo que acostumbraba". (pág. 33). Se necesita, pues, poseer un material, unos conocimientos que sean suficientemente acertados que muevan e impulsen a querer realizar el esfuerzo de permanecer abiertos a las incertidumbres diarias.

Define el sentido de propósito como "la sensibilidad de que el tratamiento puede cambiar una vida, por lo que el esfuerzo vale la pena" (pág. 12). Sus oponentes claros: la apatía y el cinismo.

Toca de pasada la vergüenza, la culpa, y afirma que pueden significar otras emociones, lo mismo que la curiosidad puede significar realmente ira o miedo. En el desarrollo de un paciente es necesario que encuentre formas de utilizarlas productivamente.

El disgusto, la tristeza, la depresión, la ansiedad, que resultan a veces tan insoportables que dificultan el tratamiento, y pueden paralizar al paciente cuando ha de referirse a ciertos contenidos íntimos, o incluso no arriesgarse a cambiar, y no tener deseos de compartir ni seguir para adelante. El paciente conoce sus experiencias; es el terapeuta el que, en continua participación de ambos, aportará hacia dónde dirigirse, hacia dónde enfocarlo. 
La integridad, como la consistencia entre lo que hablamos y practicamos para evitar la confusión. Y cómo la forma de estar con el paciente ha de ir en consonancia con los valores que mostramos.

\section{Tesis de la autora}

La autora se propone que tras la lectura del libro, el lector se cuestione y se sienta inspirado para efectuar interrogantes

"Cualquier sentimiento tan intenso que amenace el equilibrio, es traumático por lo menos hasta cierto punto" (pág. 183).

Las emociones pueden ser moduladoras de otras emociones porque todas forman un sistema. Toma el caso Dora, de Freud, como ejemplo, y hace una reflexión sobre la posible causa de que fallara el tratamiento. (pág. 188-199)

Un análisis "no es un misterio que ha de ser resuelto por un rastreo competente, el paciente no se encuentra ahí para ser decodificado " (pág.38)

"La valentía de la analista se muestra en intervenciones que equilibran la necesidad de tacto con la necesidad de verdad, sin sacrificar ninguna... lo difícil es ser empática y franca" (Pág. 125)

\section{APORTES, REFLEXIONES DE/SOBRE LA OBRA}

Lo mismo que en el libro "Marcando La Diferencia En La Vida De Los Pacientes. Experiencia Emocional En El Ámbito Terapéutico" (2015), Buechler sigue dando un papel esencial a las emociones en el cambio psicoterapéutico. Y las que considera esenciales para el cambio psíquico son la curiosidad, la esperanza, la afabilidad, la valentía, la finalidad, el equilibrio emocional, la integridad, la capacidad de sobrellevar la pérdida. Y ellas conectadas con el lugar que ocupan en nuestra vida.

El uso clínico de la teoría de la emoción implica tener la curiosidad como emoción fundamental, y que las emociones forman un sistema, de manera que cuando se altera una emoción afecta a los niveles de todas las demás. Por ejemplo, la esperanza, la curiosidad y el amor tienen más fuerza que la ira y el dolor.

La teoría de las emociones supone un lenguaje tanto para el analista como para el paciente, porque sabemos el papel que juegan en la vida, aun cuando no se expresen. Y esto sobre todo cuando nos encontramos con pacientes no emocionales y no relacionales, donde necesitemos proveerles de un vocabulario emocional que les ayude y que nos ayude a nosotros terapeutas, máxime cuando estos pacientes incluso nos pueden llegar a desvitalizar.

Sandra emplea de forma libre la teoría de las emociones fundamentales: gozo, sorpresa, tristeza, enojo, temor, vergüenza, y otras. Se necesita conocer cuáles son las emociones personales que usa el paciente, sus fuentes y el grado de impacto. Se detiene especialmente en definir la emocionalidad normal, y especificar las emociones una a una en particular, afirmando que las emociones no son unidimensionales. Unas emociones modulan otras emociones, 
pudiendo alterar otros afectos: por ejemplo la curiosidad puede vencer la pena, y cómo la ira supera a la vergüenza y a la timidez.

Cuando Sandra habla de la teoría de las emociones incluye que son adaptativas y sostenidas por otras emociones. Lo cual también significa que no siempre se va a hablar al paciente de las emociones que le atraviesan, porque quizá no las sabe, o quizá no le interese en ese momento debido a que su experiencia vital está en otra cosa bien distinta.

El tratamiento deberá llevar al paciente a que pueda sentir curiosidad, esperanza, alegría y capacidad de sorpresa, que le ayude a poder persistir en el trabajo, así como a soportar pérdidas dolorosas o aspectos difíciles a lo largo de la vida. $\mathrm{Y}$ a veces también al enojo como fuerza motivadora de persistir. Siendo igualmente importante aumentar su habilidad para que utilice la experiencia emocional dolorosa como una fuente de motivación e información. Será necesario provocar emociones positivas como la curiosidad, la esperanza, la alegría y el amor como modulares de la ira, la vergüenza y la soledad. Por ejemplo, que el paciente module la fuerza motivadora de la ira con otra, y lo mismo con la vergüenza y la culpa. El temor, la ansiedad, la tristeza o la envidia pueden ser una fuente de información valiosa. Y no menos importante será que el tratamiento ayude al paciente a clarificar lo que sucede interpersonalmente, desarrollando una actitud analítica. Además cuando el paciente participa en su proceso el analista se sentirá menos solo.

Afirma que el tratamiento lleva inherente una intensa lucha, para lo cual hace falta que ambos, paciente y terapeuta se doten de una energía y sobre todo de un gran compromiso que genere esperanza y una experiencia vital activa. Por ello especifica cualidades que ella considera en la actualidad de suma importancia para la vitalidad del terapeuta. Los pacientes a menudo vienen a tratamiento esperando cambiar lo que sienten. Quieren más alegría, esperanza, amor e interés y menos ira, temor, ansiedad, vergüenza, culpa y aflicción. (pág. 192)

Describe la ayuda proporcionada por Sullivan en los tratamientos: por una parte, lo que hay que clarificar como más importante, y dónde hay que fijarse cuando haya múltiples posibilidades de hacia dónde dirigir nuestra atención; por otra, buscar cuál es el significado en la función interpersonal, más que detenerse en significados simbólicos; asimismo, cuándo ocurre un comportamiento y cómo afecta a la vida interpersonal del paciente, más que por qué lo hace, que puede llevar a la repetición de racionalizaciones obsesivas. Ayudar al paciente a conectar experiencias que todavía no ha hecho.

Tiene también un recuerdo para Eric Fromm, por lo que supuso para ella no sólo leer sus escritos, sino también lo que le aportaron sus supervisores y maestros. Se refiere a su idea de ser un humano, el amor por y a favor de la vida, su pasión por el trabajo, su sentido de finalidad, la importancia de creer que lo que está haciendo es correcto, su poder creer en ella misma e insuflarle espíritu luchador contra el desaliento, el cinismo y el someterse a las presiones sociales, al no necesitar seguir órdenes instituidas en la psicoterapia de forma rígida y ciega, tener un sentido suficientemente potente de hacia dónde se quiere dirigir. Dice que nuestro lenguaje ha de huir de cualquier jerga y no perder el contacto con nuestra experiencia humana, 
con nuestra subjetividad. Lo contrario sería poner coto a nuestros sentimientos vitales y desconectarnos de nuestros recursos internos básicos

Cita a Bacon (pág.58), y dice "si un hombre comienza con certezas, terminará en dudas, pero si está contento de comenzar con dudas, terminará en certezas". Lo que significa que cuando hay un paciente con curiosidad necesita no estancarse, idear, preguntarse qué sucederá si se emplea en la búsqueda. Esto es lo contrario a una situación de defensa paranoide que busca estereotipos, concretar hacia dónde va, prever, estar en lo correcto, y nunca crear verdades nuevas. El terapeuta se sentirá entonces muy maniatado porque el paciente le urgirá a tener respuestas rápidas más que a indagar. Necesitará distanciarse de esa influencia paranoide del paciente y preguntarse si está interesado en mantener un estado rígido de certeza más que en saber la verdad. Incluso su propio miedo a la incertidumbre puede unirse a la del paciente.

¿Cuánto debe arriesgar el terapeuta en su afán de indagar para que no sea un fracaso y mantener su integridad? ¿Cuánto debe sacrificar su punto de vista? Se trata en todo caso de que no aparezcan ambos, paciente y analista, armados diestramente cada uno de su teoría y dispuestos ambos a hacerla prevalecer. En el analista ha de prevalecer la autodisciplina antes que el placer de la curiosidad y de ser visto como un enemigo desafiante; o simplemente llevar al paciente a su teoría favorita, en vez de manifestar una postura de exploración juguetona que aliente a una experiencia interpersonal con nuevas formas de ser curioso. Poder hacer conjeturas sobre lo que le falta al paciente: hablar con afectividad, rellenar esas lagunas por las cuales viene a nosotros, pero añadiendo ese componente del cual está carente, creando así un lenguaje y una manera de trabajar juntos los dos, paciente y terapeuta, con la que atravesar el proceso de la psicoterapia. Es más importante abrir la mente del paciente que el conseguir aciertos. Y que la necesidad que tenemos de ser reconocidos y valorados o de llevar razón, no invada nuestro trabajo. Así mismo estar más dedicados a ayudar al paciente que a mostrar lo que sabemos. Hay riesgos que no merecen la pena, nos viene a decir Sandra. Con ello el paciente tendrá experiencias no sólo en la sesión, sino también fuera del tratamiento.

Señala que en la clínica ha de integrarse lo que se aprende de otras ciencias, del arte, de la política en la cual estamos inmersos pacientes y terapeutas, ambos oímos lo mismo diariamente. Continuamente nos enriqueceremos también no solo con profesionales de nuestro campo, sino que utilizaremos asimismo música, literatura que hayamos leído, frases que saltan a nuestra mente, cualquier cosa que nos oriente ante un conflicto, historias de otros pacientes que recordemos, experiencias de vida, conceptos teóricos, y sobre todo nuestros recursos internos. Así nos sentiremos menos solos y todo ello nos acompañará.

Sandra Buechler cuenta que a los pacientes nuevos les pregunta por qué la eligieron a ella, por qué buscan tratamiento en ese momento, cuánto les ha incomodado el problema, la situación en la que nacieron, el entorno cultural, el contexto socioeconómico, la configuración familiar, los vecinos. Y todo eso porque es lo que conforma su experiencia como ser humano. 


\section{LA CURIOSIDAD}

¿Qué es la curiosidad? ¿una insistencia nunca satisfecha de conocer? ¿Qué interfiere la curiosidad, qué la evoca, qué la produce? La respuesta que nos da Sandra es: "debemos adorar las preguntas y mantener una imparcialidad verdadera ante nuevas ideas, valorándolas sin importar que las creencias que abriguen nos sean opuestas... debemos tener un impulsor: la necesidad apasionada de conocer, más allá de ese rincón de nuestro propio "espacio", y encender un deseo ardoroso semejante en los demás." (pág. 68)

¿Qué puede inhibir la curiosidad cuando el paciente se aventura a entrar en un territorio nuevo? De forma significativa la defensividad paranoide, porque habrá oposición a indagar en lo desconocido, insistirá en sus certezas, estrechará la visión, suprimirá la duda, se opondrá a ser sorprendido, no deseará arriesgar

Hacerse preguntas por curiosidad de saber más del paciente: ¿cómo es mi paciente en esta circunstancia? ¿cómo puedo ayudarle a que se reconozca a si mismo? ¿cómo es nuestra relación con lo desconocido?

Sandra cita a Mc Dougall (1908) quien afirma que el estímulo que provoca la curiosidad es estar abiertos a la novedad, a la extrañeza. Pero en razón inversa. Es decir, cierto grado de extrañeza agudizará el sentir curiosidad, desearemos explorar, investigar los cambios que se producen en nuestra vida para que no pasen inadvertidos, nos intrigará. En cambio, si el grado de extrañeza es demasiado grande aparecerán defensas temerosas. Por ello, es necesario encontrar dentro de lo extraño algo que resulte familiar. Pero al mismo tiempo, la curiosidad activa tendrá que ver también con aquello que se separe de lo muy familiar. Son esa curiosidad e interés por lo desconocido lo que motivará ir hacia un enfoque determinado. Cuenta el ejemplo de una paciente que fue a la sesión con el pelo cortado. Sandra no se dio cuenta, porque no le suscitó interés. La paciente echó de menos un comentario e hizo su propia interpretación: no le ha gustado y ha sido educada al no decirme nada para no herirme.

Excitar la curiosidad ante un paciente para elevar la claridad de nuestra finalidad. Cuando la curiosidad ha aparecido en el paciente repercutirá en su tratamiento, ayudándole a pesar de que sienta dolor, o atraviese grandes dificultades

Cuando el analista es curioso provocará la curiosidad del paciente. Pero la curiosidad como opuesta a la paranoia, como un continuum desde la mentalidad abierta y curiosa a la cerrazón de la mentalidad paranoide. Cuando aparece la ansiedad paranoide existe un gran obstáculo para la curiosidad. De ahí la importancia de saber manejarla. Por eso propone que el terapeuta ha de resolver los huecos de paranoia que haya en él mismo y en el paciente. Habrá que entender la paranoia buscando qué es lo que evita y lo que desea conseguir

Describe seis funciones de la curiosidad del analista con vistas a estimular la del paciente. La curiosidad del analista es esencial para:

1.- Hacer un enfoque selectivo cuando hay mucho material en la sesión, y en palabras de Sandra, cuando aparece "un teatro de posibilidades simultáneas". La curiosidad nos hará fijarnos en algunos temas y abandonar otros por el momento, ver qué historias son más 
relevantes, poder formar pensamientos y darles significado, conectar con nuestra contratransferencia, crear hipótesis, hacer asociaciones.

2.- Crear un contexto donde se puedan dar intercambios importantes, motivar a la interacción hacia un interés mutuo, partiendo de que el analista no es ni padre ni amigo. Ambos, paciente y terapeuta, dan un sentido a la sesión con la cual puedan interactuar juntos, preguntar y preguntarnos. Al conocer pacientes nuevos concentra su curiosidad como clínica, pero después se centra en la del paciente, elaborando la historia y la razones para buscar en ese momento un tratamiento, haciendo preguntas que muevan a la curiosidad. Eso crea un ambiente favorable para el trabajo.

3.- Promover la integración de si mismo con los diferentes pacientes, de tal manera que se haga familiar lo extraño y lo extraño familiar, y ello para ayudar a las personas a desarrollar la coherencia consigo mismas.

4.- Advertir lo que no se haya registrado anteriormente. Hace referencia al aforismo de Levenson (citado en el libro pág. 52) "el último en saber sobre el agua es el pez". Es decir que el paciente se llegue a plantear interrogantes acerca de situaciones que le pasan desapercibidas, y con ello "hacer de lo familiar algo extraño. Algo que el paciente da por sabido enteramente, es cuestionado por el analista" (pág. 52). investigar sobre ello con curiosidad

5.- Conducir la investigación de manera detallada, siguiendo a Sullivan y Levenson (citados en el libro pág. 53) Levenson afirma que el analista debe preguntarse ¿Qué está pasando aquí? En lugar de ¿Qué significa? Para ello busca ampliar la investigación sobre los hechos que ocurren, y va preguntando en espiral sobre lo que el paciente narra y lo que ocurrió en el pasado. Sandra afirma la existencia de tres pasos esenciales:

- establecer el encuadre y cuáles son las expectativas del paciente

- advertir si hay datos que no aparezcan en el material aportado, que el terapeuta los eche en falta, y la curiosidad le lleve a preguntarse por qué faltan. Con ello se enriquecen datos y se evitan defensas. En este sentido Sullivan habla de investigación detallada, que marca una apertura mental y la responsabilidad individual, desechando la culpa. Importante en este sentido, cómo trata el terapeuta la interacción con el paciente mientras pregunta para obtener más información. ¿Es interés? ¿Es una insistencia rígida paranoide, o una "violación verbal? ¿Cuida las vulnerabilidades del paciente para no lastimarle?

- poner en funcionamiento los aspectos centrales de la transferencia y contratransferencia

6.- Que se refleje en la contratransferencia. Para este tema de la contratransferencia Sandra remite a Mitchell 1993, 1997, Renik, 1993, Hirsch 1995, Buechler, 1999, Maroda, 1999, 2002. Utilizar siempre la contratransferencia como información de los dos participantes. Pero en absoluto como una fuente de vergüenza, de culpabilidad, de ansiedad, de repugnancia, de cólera y de desprecio. expresa. Este material es para uso científico y profesional exclusivamente y puede contener información clínica sensible. Los editores no se responsabilizan de los contenidos de los autores. Dirigir las consultas sobre derechos y autorizaciones a ceir@psicoterapiarelacional.es 


\section{LA ESPERANZA}

Dice la autora que "aunque está claro que quienes participan en un tratamiento necesitan tener esperanza, la naturaleza de dicha esperanza es difícil de definir. La esperanza es un concepto evasivo. ...asumo un enfoque inductivo...algunas de mis propias experiencias clínicas...integrar lo que significa para el analista y el paciente." (pág. 69)

La esperanza es considerada en su parte emocional como lo que nos empuja a seguir adelante, que nos recompensa en el presente, y nos influye en un aspecto cognitivo: la expectativa de transformación en el futuro, el deseo de que ocurra algo, la expectativa anhelante de que las cosas cambiarán para mejor, lo cual es menos impulsor y puede ser útil, aunque puede no ser tan potente como para sostener el tratamiento. Para esto es necesaria una experiencia emocional activa, y en conjunción con la fe a la que la esperanza se une. El analista representa ambas. "El paciente y el clínico no pueden tener una esperanza duradera, sin una fe duradera". (pág. 73). "Es posible estar emocionalmente esperanzado en ausencia de grandes expectativas, si el contexto interpersonal lo fomenta. Fomentar la suficiente esperanza es una de nuestras tareas centrales"'" (pág. 89)

Sandra habla de tener esperanzas equivocadas que generan desaliento. Po ejemplo la del paranoide cuando desea un resultado predecible. Esta es una estrategia perdedora por ser imposible. O el narcisista cuando busca reflexiones que fomenten su ego, De ninguna manera se sentirá tranquilo porque es una esperanza deficitaria y a medias. O los pacientes con trastornos de la alimentación que nunca están satisfechos. O la esperanza del obsesivo al que tampoco su estrategia es válida. O la frustración del esquizoide controlador.

¿En qué consiste la esperanza del analista? En su convicción personal: en sentirse seguro de que está haciendo todo lo posible para que el paciente progrese, en saber que puede esforzarse más allá de lo razonable, en tener un fundamento, en saber que nada o casi nada puede detenerle, en poder contar consigo mismo, en autoconocer su firmeza y determinación, en creer que lo que hace es valioso. Y eso impulsa a seguir hacia delante.

Como las otras emociones humanas, también la esperanza ha de ser considerada junto a otras emociones dentro del sistema formado en el ser humano, en el cual unas emociones se modifican con la estimulación de otras a las cuales acompaña, por ejemplo con la alegría, o con la vergüenza, o la ansiedad. La esperanza se modifica cuando existe una curiosidad, o cuando existe la sorpresa

¿Cómo se transmite la esperanza? Sandra afirma que a través de nuestros valores durante el tratamiento: nuestra perseverancia de no rendirnos, nuestra resiliencia, cuando aceptamos nuestra dificultad, a través de nuestro tono, de nuestra convicción, del humor, de sus silencios, de lo que habla en primera persona, y cuando nos enfrentamos con honestidad a nosotros mismos. Por supuesto, a través de las muchas estrategias que empleamos para calmar, para aplacar el dolor, la angustia, la desesperanza a veces...

Sandra habla de la apasionada fuerza de la esperanza. Y cita a varios autores: A Mitchell quien en su libro Esperanza y Temor, habla de que "las esperanzas de la analista para sus pacientes 
están incrustadas en su propia identidad, su valor, lo que puede ofrecer, lo que ha encontrado profundamente significativo en su propia vida" (pág. 141). También le sigue apoyando su idea acerca de que los analistas hablan o escriben poco de la esperanza. Eso le impulso a ella a escribir sobre esta emoción. A Erich Fromm diciendo que "tener esperanza significa atreverse, pensar lo impensable y, con todo, actuar dentro de los límites de los realmente posible... la esperanza no es pasiva... es impaciente y activa, busca toda posibilidad para la acción dentro del campo de las posibilidades reales" (pág. 89). Y a Menninger: "El exceso de esperanza es presunción y conduce al desastre. La insuficiencia de esperanza es desesperación y lleva a la decadencia" (pág. 89)

\section{LA DESESPERACIÓN}

Expresa el sentimiento de que las cosas no van a cambiar nunca y por tanto el dolor será interminable. Las personas con depresión están en una situación de desesperanza por amenazas fatales, o enfermedades exageradas. Buechler estudia esto también a través del desgaste de los analistas, y afirma que cuando se da tal desgaste, supone una pérdida de fe en la profesión, en su progreso, se sienten desmoralizados, no tienen expectativas, a veces por el estrés no tienen ni energías. El problema está cuando por razones económicas ha de seguir trabajando. El desgaste viene a decir Buechler es una respuesta desesperada a tanta pérdida acumulada, tolerada de forma estoica y en silencio. "El analista desgastado ha sufrido la más grande pérdida posible al perder la fe en el valor de sus talentos profesionales." (Pág. 207)

\section{LA BONDAD}

Se refiere a experiencias personales como parte de la acción terapéutica. Cuando se dan actos de bondad en el tratamiento se satisface el anhelo del paciente de tener importancia. Éste siente una demostración clara de que alguien valora sus esfuerzos. Pueden ser actos triviales, sutiles, que incluso pueden pasar desapercibidos en un primer momento, pero a largo plazo son valorados y además, este valor va aumentando cada vez. Por ejemplo: no comentar nada cuando el paciente ha tenido un lapsus para que no se sienta avergonzado, tratar un asunto en lugar de otros. Es dar importancia a los sentimientos del paciente.

"El tratamiento no es viable sin alguna bondad demostrable, por lo menos de parte del clínico hacia el paciente. Sin algunos actos de bondad, el tratamiento se atasca o termina....su manifestación en un intercambio, refleja el nexo de dos personalidades particulares con vidas específicas" (pág. 98) .

Algunas formas de la bondad, referidas al terapeuta y que se presentan con frecuencia, se basan en el sacrificio temporal de la ecuanimidad, del funcionamiento cognitivo y emocional y del orgullo. El temor a ser bondadosos puede obstaculizar.

Enumera como actos de bondad y sacrificio lo que hacen los clínicos con frecuencia: Exposición a traumatizaciones vicarias. El sacrificio de la cesión voluntaria de la tranquilidad, es decir el 
número de emociones que soporta por el bien del tratamiento: culpa, temor, soledad, ansiedad, envidia..., el dolor. Ser contenedores del sufrimiento humano. Tener experiencias de torturas políticas. Pacientes psicóticos hospitalizados, con la dureza y el peligro y la desesperación de ese mundo. Historias de abusos infantiles y los riesgos de si informar del abuso y perder la ocasión de tratar al niño, o luchar con la culpa de hacer más daño al niño. El trabajo con personas mayores, con viudas recientes

Es decir, dolor vicario que nos estremece profundamente, humores cambiantes, dificultad para poder pensar y sentir, la sensación de soledad, confusión ante la aparición de ciertos sentimientos, el sentimiento de no ser nosotros mismos, el sacrificio del propio orgullo, etc, son lo valores que se actúan al exponerse a si mismo, sin tiempo en muchos momentos para el propio proceso de recuperación, asimilar el impacto y dejarlo a un lado ante el siguiente paciente, sin dejar entonces que los sentimientos anteriores obstaculicen la experiencia siguiente. Supone un balanceo del equilibrio emocional.

Sobre el final del tratamiento y las dudas acerca de si es mejor o no, será un vivir con constante incertidumbre y sorpresas. Tendrá necesidad de pensar rápidamente y estar disponible psicológicamente. Soportar muchos secretos

\section{LA VALENTÍA.}

Hablar de la valentía clínica como emoción supone poder tolerar la vergüenza, la culpa, la ansiedad, a veces la soledad del propio punto de vista, o la sorpresa. "Freud y otros pioneros del psicoanálisis, necesitaron enorme valentía y libraron sus propias batallas ellos solos" (pág. 135)

Buechler de entrada cree que se requiere mucha valentía para ejercer la clínica, porque son muchos los interrogantes que le plantean al terapeuta sobre enfermedades, preocupaciones y conflictos de los pacientes, aun cuando éstos no presenten un gran riesgo. Siempre que tenemos sesión pueden aparecer nuestras vulnerabilidades, incluso algunos pueden perder el ánimo y el valor, y sentirse consumidos.

Y cuando el terapeuta se encuentra con un paciente que ha sufrido por ejemplo, abuso físico, o que se presenta muy irritable y desbocado, o aquel que vive en un mundo amenazante y su mente se trastorna siendo capturado por fuerzas ajenas, ¿hasta dónde puede la terapeuta explorar sin perder la seguridad de que el paciente tenga peligro de descompensarse? Y la terapeuta, ¿cómo atiende a su sentimiento de peligro cuando está aterrada con las descripciones de las historias, o el potencial peligro que puede correr con la potencial actuación del paciente descompensado? Buechler habla de que en ese momento "todo depende de que la terapeuta tenga valentía suficiente y sepa fomentarla para el paciente. En última instancia, el valor cuenta más que cualquier percepción de las fuentes de perturbación." (Pág. 116). Es claro que en casos así hace falta una gran valentía y práctica cuando ha de confrontar a pacientes que resultan impredecibles, sin sucumbir al miedo ni negarlo.

¿De dónde conseguimos los terapeutas tener el valor necesario para que podamos mantenernos firmes? Porque está claro que nunca podremos aparecer asustados, ni atemorizar 
al paciente. Al revés, necesitamos seguir pensando sin perdernos y entender al paciente. ¿Hasta cuándo y hasta cuánto puede el terapeuta mantenerse con un paciente que está descompensado o en peligro de descompensación, sin que resulte demasiado insoportable? También se plantea Buechler ¿qué es lo correcto para ayudar a un paciente con el que hay que hurgar en el pasado para buscar evidencias?, ¿cuál es nuestra responsabilidad?, ¿cuáles son nuestros propios valores, nuestros enfoques sobre esas evidencias que buscamos? O sea "para cada tipo de carácter, la situación óptima es que el analista experimente, en un grado moderado en lo personal, los temas centrales del carácter del paciente" (pág. 119)

Buechler nombra a Aristóteles, que en el siglo IV a. C, en la Ética a Nicómaco "define la virtud de la valentía como la observancia hacia del punto medio entre el temor excesivo y la precipitación excesiva (pág. 67).

Cuenta como ejemplo una viñeta de Altman sobre una paciente suya que le tenían que hacer una cirugía cerebral y reinsertarle una pieza en el cráneo. En la sesión antes de la operación, la analista " tenía que caminar sobre la cuerda floja entre reaccionar de más o de menos ante la situación. El objetivo de la analista era que la paciente fuera dueña de su ansiedad y no la transfiriera a la analista (lo cual se puede inducir si la analista reacciona de más), o se distanciara de ella (lo cual podía ser generado por una reacción de menos de la analista)" (pág.136)

Pero Buechler dice que no es tan sencillo. Ella habla de que la práctica ayuda a poder soportar situaciones que evocan miedo, y puede compensar nuestras tendencias naturales corrigiendo aquello que no es sano en nosotros y a lo que podemos ser más propensos. Siempre teniendo en cuenta el carácter del paciente. Nombra a Kantrowitz (1996) quien estudió los informes que hacen los analistas sobre el propio impacto que les producen los pacientes. Y llegó a la conclusión de que el carácter de un paciente puede resultar relevante o no para determinados tratamientos. Por ejemplo, con un paciente esquizoide, irán bien los temas como la intimidad del analista, las dificultades con las emociones intensas. Si por el contrario se trata de un paciente obsesivo el analista podría entrar fácilmente en batallas por tener el control de la autoridad. De este modo, los pacientes responderán de forma defensiva a las interpretaciones e insistirán en sus propias afirmaciones con argumentos lógicos e intelectualizados. Nunca las confrontaciones son deseables, porque ambos se pueden enredar en discursos aparentemente lógicos pero infructuosos a la hora de producir cambios en la forma en que el paciente interactúa en su vida. En algún momento pueden requerir de la valencia del terapeuta, que dispone de técnicas como el análisis de la defensa por ejemplo. Puede incluso el analista ser demasiado obsesivo y no ver lo que el paciente se sacrifica por él. Si tratamos a un paciente narcisista y el analista lo es también, necesitará especial cuidado para no lesionar la autoestima del paciente, confrontándole antes de tiempo, o con un lenguaje brusco que le provoque ansiedad y se sienta en peligro. Otro modo sería que debido a su propia timidez, ofrezca al paciente falsas palabras tranquilizadoras, no arriesgue, y pierda de vista intervenciones que pudieran resultar valerosas. En todo caso, se trata de que los rasgos del carácter del paciente, resulten de algún modo familiares en lo personal del terapeuta, pero sin que se sienta abrumado para poder seguir adelante y conducir al paciente a la reflexión.

\section{CeIR Vol. 12 (3) - Octubre 2018 ISSN 1988-2939-www.ceir.info}

() Derechos reservados/Copyright de Clínica e investigación Relacional y los autores. Prohibida la reproducción total o parcial sin autorización expresa. Este material es para uso científico y profesional exclusivamente y puede contener información clínica sensible. Los editores no se responsabilizan de los contenidos de los autores. Dirigir las consultas sobre derechos y autorizaciones a ceir@psicoterapiarelacional.es 
Buechler afirma que "un analista que vive cada sesión con valentía, a veces nombrando los peligros, pero aun así luchando por salir adelante, fomenta la valentía en el paciente" Y Cuenta una viñeta personal a propósito. (pág. 137)

Por todo ello Buechler se pregunta qué es lo que se debe confrontar, cuándo y cómo, o qué se debe escuchar y dejarlo por el momento así. Ella misma contesta: la valentía clínica depende de lo cómodo que cada uno se sienta con su superyó, es decir que siempre podamos confiar en que podemos vivir tranquilos con nosotros mismos, sea cual sea el resultado.

\section{EL SENTIDO DE PROPÓSITO}

En este capítulo explorará lo que denomina el sentido de propósito como necesario para el tratamiento. Buechler afirma que no sólo nuestras metas como analistas son personales, sino que tanto analista como paciente necesitan tener una misma curiosidad, una misma esperanza, un equilibrio emocional, la habilidad para soportar la pérdida. La analista ha de ayudar al paciente pero no excluyendo sus propias necesidades personales.

El ideal de la neutralidad en el psicoanálisis clásico obstaculizó esto y "no permitió suficiente espacio para la expresión de las pasiones contratransferenciales... e hizo difícil encarar los anhelos que traemos a nuestro trabajo, expresarlos con los pacientes y con cada otro, y para confrontar el valor que la profesión le da a tener un sentido de propósito" (pág. 142-143). Y todo ello teniendo presente el deseo de que el tratamiento avance. Tener un sentido de propósito, una finalidad personal incluirá una expectativa de progreso, avanzar hacia una vida más normal. Esto es algo esencial a tener en cuenta para ambos, analista y paciente. Una ayuda grande para tener sentido de propósito supone crear significado.

Algunas personas son capaces de encontrar propósito, pero otros van a la deriva sin ningún propósito por la vida. Es como si lo bloquearan, terminando en una desesperanza porque ha sido destruida. Es como que se quedan sin argumento, sin dirección aun cuando en otro momento de la juventud pareciera que estaban bien equipados para la vida. Pero después son incapaces de encontrar con seguridad el significado de sus vidas. Es bien claro esto cuando ciertas personas se jubilan y no saben como organizar sus vidas, sin la energía que requieren. Quizá el elogio daba significado a sus vidas y cuando el elogio se acaba, la motivación se va.

La cuestión es cómo se encuentra el impulso motivador interno para poder vivir de otra manera distinta. A veces cuando preguntamos a un paciente qué le gusta hacer en su tiempo libre no sabe qué decir, y se queda callado porque nunca se lo planteó. O todo lo contrario algunas personas siempre están activas para no pensar, para no caer en depresión. Que es lo mismo que decir ¿quiénes serían esas personas sin esa actividad continua?

Somos nosotros, sabiendo lo que nos da significado, los que transmitimos con pasión y ánimo de lucha, los valores que encontramos significativos, y que nos dan un sentido de propósito. "Dice Buechler que "el pintor Wassily Kandinsky dijo una vez que cada pincelada debía venir de la "necesidad interna". Cuando perdemos el tirón de la necesidad interna, completamente, la vida crece vacía de propósito. Como analistas, cuando nuestro trabajo pierde el sentido del 
propósito, hemos capitulado hacia el agotamiento.... El agotamiento es una pérdida terrible. Es una pérdida de fe en la profesión y en si mismos...un ejercicio vacío" (pág. 160-161.)

\section{EI EQUILIBRIO EMOCIONAL}

Este concepto de equilibrio emocional tiene para Buechler tres consecuencias:

1.- Comprensión particular de la empatía. La empatía no es un registro y reflejo exacto de emociones. Es un equilibrio emocional de parte del analista con el que el paciente se llega a identificar. (En su libro posterior "Marcando la diferencia en la vida de los pacientes", (2015), se detiene bastante en describir y analizar este tema de la empatía

2.- Comprensión de la acción terapéutica como modulador de emociones intensas

3.- La defensa como una forma de hacer frente a afectos intensos, pero reconociendo el poder que tiene la emoción de modular otras emociones. $Y$ esto es porque las emociones forman un sistema y cada emoción afecta a todas las demás. Por ejemplo, una persona puede defenderse de sentir que su alegría ha disminuido, lo mismo que puede hacerlo con la vergüenza o la ansiedad o la culpa.

Puede haber momentos donde se puede perder ese equilibrio emocional, por ejemplo, cuando se siente temor, o enfado, o ansiedad, o curiosidad, etc. Pero si el terapeuta utiliza adecuadamente, durante la sesión, la forma de recuperar esas emociones y lograr el equilibrio, el paciente puede integrar esa experiencia dentro de su estilo emocional. Ahora bien, no como una simple imitación de cómo se enfrenta el terapeuta, sino por el hecho de estar con el terapeuta, cerca de él y tener un sentimiento interpersonal de cómo se lucha para conseguir el equilibrio. Ahí es cuando el paciente lo hace concordar con su propio estilo emocional.

Para Buechler el concepto de equilibrio emocional supone varias cosas:

1.- No tratar de disminuir la emoción que el paciente trae al tratamiento, sino tratar de impactar en otra emoción, y de esta manera afectar al sistema entero. Por ejemplo, si viene un paciente muy desesperado no se trataría de disminuir su desesperación, sino enfocar otra emoción que sea más fácil de cambiar en ese momento.

2.- Cuando un paciente acude a tratamiento viene sin entender de forma cognoscitiva porqué le ha ocurrido la experiencia que define. Cuando va experimentando un cambio en su conducta, puede crear un equilibrio emocional diferente porque disminuye emociones que le puedan haber influido y con ello crear probablemente nuevas experiencias.

\section{LA DISOCIACIÒN}

Parte de que no es la cognición la que puede alterar las emociones. Desecha la idea clásica de que son las defensas, las técnicas cognoscitivas que el yo usa en los conflictos, las que le llevarían a la neurosis. Y nombra como ejemplo todas las defensas conocidas que denominó Anna Freud (1966): regresión, represión, formación reactiva, aislamiento, anulación, 
proyección, introyección, la vuelta contra si mismo, la transformación en lo contrario). Buechler, por el contrario, defiende que son las emociones las que tienen el poder tremendo de alterar otras emociones. En ese caso las defensas serían la utilización de medios principalmente emocionales, esfuerzos afectivos para mantener un equilibrio emocional, poniendo coto a sentimientos como la vergüenza, la ansiedad, la culpa, el temor, la ira, la pena, las amenazas a afectos como la alegría y la curiosidad.

Relacionándolo con el trauma, cita a Freud (1926) y dice: "cualquier cosa que amenace con trastornarnos emocionalmente puede considerarse traumática" (pág.183)

La disociación se produce cuando la persona experimenta emociones muy difíciles y, además, de forma simultánea. Lo que hace entonces es intentar separarlas. Tenemos el ejemplo de la ansiedad, con la cual disociarse resulta efectivo. O por ejemplo cuando se tiene alegría, hay serenidad, es como que todas las cosas están en su sitio, no hay pensamientos ni sentimientos que perturben. Pero cuando proyectamos tratamos de soslayar una parte de nuestros aspectos contradictorios y evitamos poner en marcha una defensa cognitiva, como la culpa, la vergüenza y otros sentimientos, o usamos la anulación que nos ayuda frente a la ira. Cuando nos falla la adaptación tendemos a buscar otra emoción. $Y$ es porque la emoción es un modulador poderoso. Por ejemplo, cuando estamos furiosos nos olvidamos de otros sentimientos. No es que dominemos otras emociones, es que las sentimos de una forma diferente. Con ello el equilibrio de modular las experiencias emocionales está en la base del proceso de tratamiento.

\section{LA PÉRDIDA.}

La autora se plantea interrogantes: ¿cómo aceptamos los seres humanos lo insondable e intolerable de las pérdidas, de la muerte, e igualmente ¿cómo afrontamos, sin llegar a morirnos, la realidad del nunca más? ¿Cómo salir adelante cuando se pierde a un ser querido? ¿Y cómo ayudamos nosotros a que los pacientes puedan desarrollar la fuerza con la cual soportar las pérdidas más dolorosas de la vida? ¿Como seguir manteniendo el coraje como analistas con tantas pérdidas de pacientes a los que hemos seguido en nuestras sesiones y que finalmente nos han dejado o nos dejarán?.

Podemos afrontarlo cuando se trata sólo de una pérdida, aun cuando sea muy dolorosa, porque los obstáculos que puedan llevarnos a una situación defensiva serán reconocidos y por tanto se podrán modificar. Este sería nuestro trabajo: dirigir el equilibrio total de las emociones, posibilitar un apoyo interpersonal. Lo peor es cuando la pérdida se mezcla con otras emociones; vergüenza, soledad, etc. Ella lo plantea con la premisa de que la pérdida puede ser tolerable si no está acompañada de otras emociones dolorosas. Por ejemplo, cuando se añaden otras como la soledad, el arrepentimiento, la vergüenza, la desesperación, esas son las que complican la pérdida. Cita a Freud en Duelo y Melancolía, éste habla de que la melancolía supone la existencia de una ambivalencia, y eso complica la pérdida. Otras complican también, como la autocrítica, la culpa. Y es necesario contrastar cuándo predomina solo una emoción, por ejemplo, la pena. En la depresión se suelen combinar varias emociones.

\section{CeIR Vol. 12 (3) - Octubre 2018 ISSN 1988-2939-www.ceir.info}

@ ( Derechos reservados/Copyright de Clínica e investigación Relacional y los autores. Prohibida la reproducción total o parcial sin autorización expresa. Este material es para uso científico y profesional exclusivamente y puede contener información clínica sensible. Los editores no se responsabilizan de los contenidos de los autores. Dirigir las consultas sobre derechos y autorizaciones a ceir@psicoterapiarelacional.es 
El tratamiento analítico proporciona muchas ocasiones para tratar la pérdida

\section{EL ARREPENTIMIENTO}

Da mucha importancia a este sentimiento. Sandra se opone a la idea de Freud de que en el duelo es necesario recordar a la persona perdida para así liberarse de ella. Buechler afirma que eso precisamente puede aumentar la soledad del paciente y exacerbar la pena. Dice que, por el contrario, hace falta retener más que abandonar los aspectos de la persona perdida para soportar la pérdida. Hace falta el mantenimiento del vínculo interno y la presencia externa de otros con los que compartir una construcción social de los recuerdos de la persona perdida, y así pasar a formar parte de sus vidas actuales.

Buechler sugiere que en las sesiones tratar el dolor es poco útil. Ahí pueden entrar en juego otras emociones moduladoras.

\section{LA VERGÜENZA}

La vergüenza es la única de las emociones que se empeora cuando se llama la atención sobre ella. "Nuestra contratransferencia hacia la vergüenza puede ser más intensamente negativa que hacia otras emociones que son identificadas menos con el narcisismo" (Pág. 202).

Efectivamente la pérdida puede crear la emoción de vergüenza, lo cual podría complicar la pena. De hecho, Freud la excluye. Y es que la pérdida puede no significar únicamente que otra persona murió, sino lo que esa persona significaba para el otro, el papel que jugaba respecto del otro y sus posibilidades. Es decir, la pérdida se alía con la culpa, o el arrepentimiento, o la vergüenza, o la soledad. La pérdida entonces es algo más complejo que incluso puede afectar al self y empobrecerle. En este caso puede aparecer la depresión. También puede aparecer esta pérdida en la vergüenza que una mujer puede sentir por no haber sido madre cuando le llega la edad no fértil.

Cuando una persona esta triste, debe estar triste y sería un error tratar de curarla de eso, mejor ayudarla a cómo estar triste o como estar solo con la tristeza, o a veces utilizar un foco diferente, afirma Buechler. "La vida duele, como analistas no podemos hacer nada para cambiar eso, pero capacitamos a las personas para soportar este dolor cuando nos centramos en las otras emociones que también sienten". Pág. 205.

\section{COMENTARIOS FINALES.}

Buechler nos advierte de la libertad con que usa el significado de las palabras paciente, analista, terapeuta. Todas ellas se refieren al tratamiento psicoanalítico, principalmente el que procede del trabajo de analistas de orientación interpersonal, pero sin tener intención de hacer distinciones finas, sino lo que ha aprendido de su propia práctica clínica. 
Es un continuo en Sandra el gusto por explorar valores emocionales. Se pudo ver en su obra: "marcando la diferencia en la vida de los pacientes", (2015). Ahora las recalca como un valor mayor y acentúa que los valores clínicos son valores humanos.

Me sigue resultando conmovedor cómo muestra con sencillez lo que piensa, lo que siente de modo personal. Poco psicoanalistas leo que se dirijan en este sentido. Es de mucho valor el que siempre se atreva a confiarnos honestamente una parte de su vida personal y profesional, y cómo aprende de las experiencias de los otros.

A lo largo de todo el libro pondrá muchas viñetas de pacientes suyos o de los autores que nombra, lo cual nos ayuda a comprender mucho mejor el significado de lo que está explicando. E igualmente, nos habla de su "coro interno" ese acompañante suyo íntimo de las personas significativas para ella, donde encuentra ideas escritas, teorías con las que le ayuden a reflexionar y a compartir y a hacerlo parte de si misma.

Me resultan de mucho valor ciertas citas de Stephen Mitchell y Rainer María Rilke sobre la esperanza, el entusiasmo y el amor por la investigación analítica, sobre la misma relación analítica y la soledad que a veces conlleva, y sobre la acción como predecesora del pensamiento en ocasiones, como expresión de lo desconocido y no nombrado.

Aboga por aprender conceptos nuevos que ella cree que son sumamente interesantes tales como la generación de la esperanza, el cultivo de un sentido de finalidad o la curiosidad. Llevo varios años leyendo y escuchándola hablar con entusiasmo de estos temas, dándoles prioridad, especialmente a la curiosidad y la esperanza, y resulta valioso ver que alguien con una autoridad como es la de Sandra Buechler, las priorice ante falsas incertidumbres de épocas pasadas. Su argumento: "la gente lucha por aquello en lo que cree". (pág. 31). Y tener en cuenta que para ayudar a otra persona deben suceder muchas cosas: paciencia, imparcialidad, disposición y tolerancia hacia esas mismas.

Cuando se trata del tema de la valentía Buechler afirma que: "puede ser necesario contrarrestar la presión del paciente y nuestro propio impulso de dejar pasar la sesión con un mínimo de esfuerzo" (pág. 123). Que buena experiencia terapéutica esta de no ser demasiado tímidos o demasiado impulsivos a la hora de interpretar lo que dice un paciente.

Me ha gustado mucho a propósito de la curiosidad, la referencia que hace de Levenson (1991, citado en el libro: "clarifique primero el "problema que se presenta", y después trabaje en establecer el encuadre y conseguir una historia cuidadosa" Para Sandra "ese encuadre incluye la expectativas del participante para el trabajo y se negocia a través del tratamiento... la historia se compila y se enmienda continuamente. Está claro para mí que es, por lo menos parcialmente, un ejercicio de curiosidad ". (pág. 50).

Nunca se me ocurrió pensar en la esperanza como una dádiva, tal como expresa Sandra. Un regalo interpersonal, de confianza sostenida de los pacientes que persisten en acudir a las sesiones en busca de cambio y ayuda, y eso a pesar de los baches y los vaivenes en la curación. Si, realmente tiene razón Sandra que cuando los pacientes perseveran a pesar de todo, significa que siguen acudiendo porque creen en nuestra integridad, en nuestros juicios, en nuestras 
buenas intenciones y en nuestra propia esperanza, porque si no tuviéramos nosotros esa esperanza no continuaríamos. Y nosotros continuamos porque creemos en ellos. Y así ambos tenemos la esperanza en un trabajo conjunto.

Qué delicadeza la forma poética con que hace la descripción de un enfermo mental. Lo describe así: "cuando su mente se desorganizó, hubo que hospitalizarlo. El infierno se había vuelto demasiado real, demasiado presente. Ya no era un escenario imaginativo para su escritura: se había vuelto un lugar de residencia. (Pág. 115)

Buechler en su ten con ten de cuál sean los límites a los que nos tenemos que enfrentar, tiene clara su postura: no se mide la valentía por el esfuerzo, ni por la profundidad del proceso, dándole a esto más valor, sino por definir cuáles son los límites, cuándo es el final de la exploración, asumir posibles intervenciones imperfectas y aceptar las consecuencias, naturalmente habiéndolas sopesado. También es valentía para Buechler el riesgo de no poder ayudar, cosa que nos ocurre en algunas ocasiones. Entonces es que el analista es capaz de sobrellevar la culpa, o la vergüenza o el arrepentimiento, porque cuanto más nos demos cuenta de la complejidad de nuestra tarea más valentía se requiere para seguir adelante.

Me parece muy interesante cuando hablando del sentido de propósito, o la actitud de tener una finalidad, una actitud en busca de un significado que cada analista y paciente deben tener conjuntamente, afirma que no solo el ideal de la neutralidad ha obstaculizado, sino también el que muchos analistas trabajan exclusivamente para satisfacer las necesidades de otros, sin tener en cuenta las propias.

Narra una viñeta sobre una paciente que "personifica el afecto intenso e inestable. Cuando se enoja conmigo, su rabia impregna su cuerpo, el cuarto y mi propia conciencia" (pág. 163) es decir está dominada intensamente por sus emociones y como tal las expande por donde va. Pero es muy infeliz. Esta paciente le sugiere a Sandra decirnos, en forma personal, que le interesan a veces estos límites por lo que suscitan en ella, lo que le preocupa, lo que registra, la intensidad de sus propios sentimientos. Al leer esto he pensado en Atwood cuando al trabajar con pacientes tan difíciles expresa el sentimiento de aniquilación emocional

Estoy de acuerdo con Buechler cuando afirma que el tratamiento da al paciente un mayor acceso a su emotividad, pero no puede eliminar el impacto sentido por ciertos aspectos tristes de la vida, por ejemplo, no puede eliminar el dolor de la pérdida profunda. Es muy realista cuando dice que el clínico es tan vulnerable a los cambios emocionales como el paciente y que los clínicos a veces utilizamos la teoría para tratar de mantener nuestro propio equilibrio emocional porque no nos deshacemos de la ansiedad, la frustración o la pena. Es decir, como cualquier ser humano las emociones nos afectan.

Cuando habla de La necesidad de justicia, de tolerancia, de trato humano a los que sufren, me ha hecho recordar los escritos Donna Orange sobre el sufrimiento de los pacientes y la comprensión y la hospitalidad del terapeuta. 


\section{Referencias}

ATWOOD, G.E.: La Psicoterapia Como Ciencia Humana. Estudios de Casos Clínicos Que Exploran "El Abismo De La Locura" (2014). CEIR (Clínica e Investigación Relacional). www.ceir.org.es

BLANCO, L. (2015). Reseña del libro: "Marcando La Diferencia En La Vida De Los Pacientes. Experiencia Emocional En El Ámbito Terapéutico. www.aperturas.org nº 53 (Orig. 2008)

ORANGE. D. (2013). Hospitalidad Clínica: Acogiendo el Rostro del Otro Devastado Vol. 7 (1) . www.ceir.org.es

ORANGE, D., (2012). El Extraño Que Sufre: Actitudes Para La Comprensión Y La Respuesta Clínica Cotidiana CEIR, Vol. 7 (1) - Febrero 2013. www.ceir.org.es

ORANGE: (2016). El Guardián De Mi Hermano Recursos Para Un Giro Ético En Psicoanálisis. CEIR. Vol. 10 (1) -. www.ceir.org.es

NOTAS:

${ }^{1}$ TITULO ORIGINAL: Clinical Values. Emotions That Guide Psychoanalytic treatment; AUTORA: Sandra Buechler; AÑO DE PUBLICACIÓN: 2004; CIUDAD: Nueva York; EDITORIAL: The Analytic Press Inc, Publishers, ahora Routledge; TÍTULO CASTELLANO: Valores de la Clínica. Emociones que Guían el Tratamiento Psicoanalítico; TRADUCCIÓN: Revisión efectuada por Alejandro Ávila de la primera traducción castellana realizada por el Seminario de Sociopsicoanálisis, AC, México, Coyoacán, 2008; AÑO DE LA REVISIÓN: 2018; DITORIAL: ÁGORA RELACIONAL Colección Pensamiento Relacional, n²0; No DE PÁGINAS: 289.

${ }^{2}$ Lucía Blanco Rejas es Psicóloga psicoterapeuta relacional, presencial y online. Directora del Centro Sanitario: "Consulta de Ayuda Psicológica Lucía Blanco", situado en Madrid c/Numancia, 6. Piso $3^{\circ}-7$. Tfno.: 670761487. Email: blancorejas@gmail.com; Titulada EUROPSY - EFPA (Federación Europea de Asociaciones de Psicólogos). Especialista universitaria en clínica y psicoterapia psicoanalítica. Universidad Pontificia Comillas de Madrid en colaboración con la Escuela de Libre Enseñanza del Psicoanálisis (ELIPSIS).; Perteneciente al Colegio Oficial de Psicólogos de Madrid desde 1.981. A la Sociedad FORUM de Psicoterapia Psicoanalítica. Vocal de la Junta Directiva de IARPP- España. Otras asociaciones: FAPYMPE, AIEDEM, etc 